Manuscript prepared for The Cryosphere

with version 3.2 of the LTEX class copernicus.cls.

Date: 19 July 2012

\title{
Sensitivity of a Greenland ice sheet model to atmospheric forcing fields Supplementary material
}

A. Quiquet ${ }^{1}$, H. J. Punge ${ }^{2}$, C. Ritz ${ }^{1}$, X. Fettweis ${ }^{3}$, H. Gallée ${ }^{1}$, M. Kageyama ${ }^{2}$, G. Krinner ${ }^{1}$, D. Salas y Mélia ${ }^{4}$, and J. Sjolte ${ }^{5}$

${ }^{1}$ UJF Grenoble 1 / CNRS, Laboratoire de Glaciologie et Géophysique de l'Environnement (LGGE) UMR 5183, Grenoble, F-38041, France

${ }^{2}$ Laboratoire des Sciences du Climat et de l'Environnement (LSCE), IPSL, CEA-CNRS-UVSQ, Gif-sur-Yvette, France

${ }^{3}$ Département de Géographie, Université de Liège, Liège, Belgium

${ }^{4}$ CNRM-GAME, URA CNRS-Météo-France 1357, Toulouse, France

${ }^{5}$ Centre for Ice and Climate, Niels Bohr Institute, Copenhagen, Denmark 


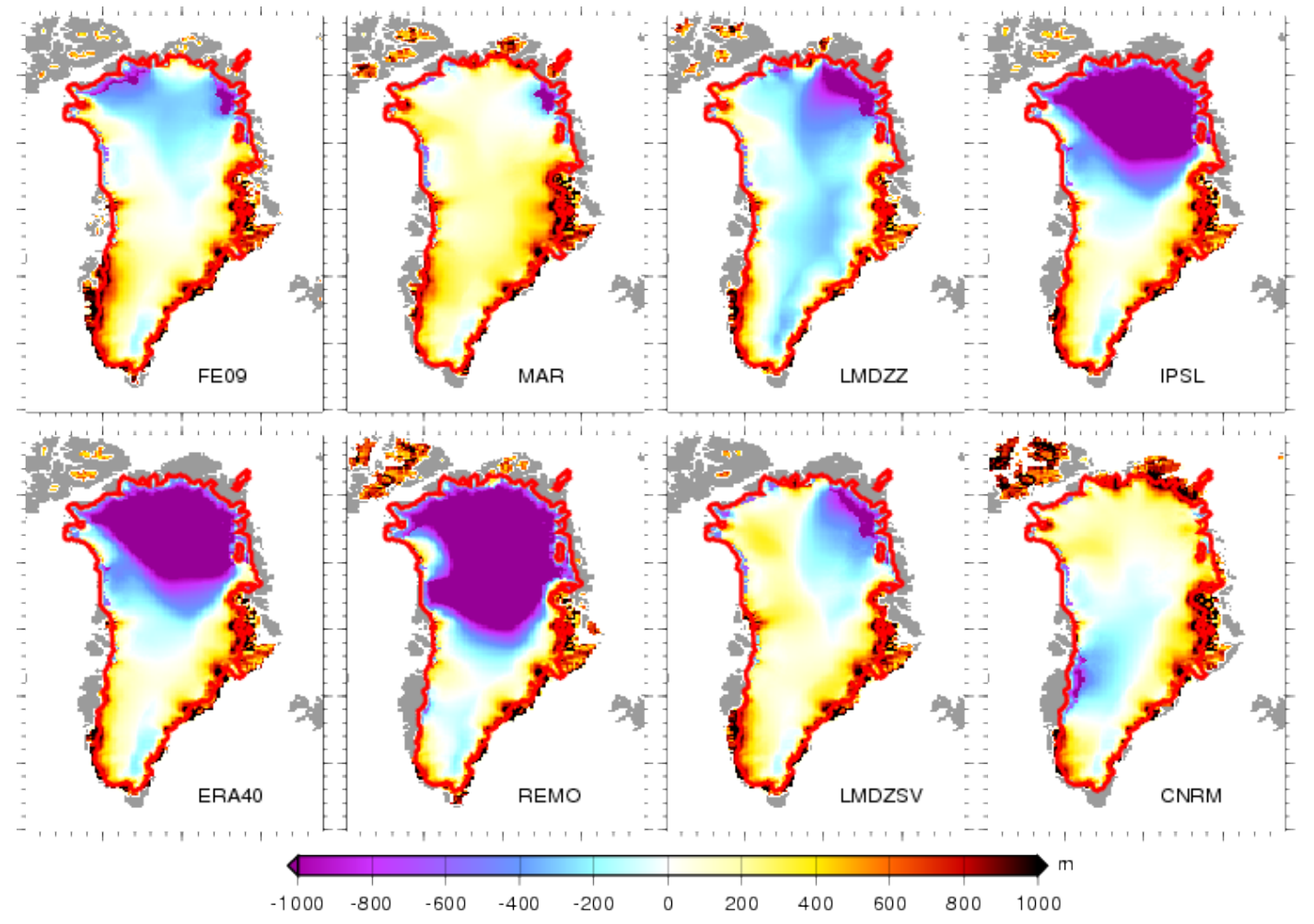

Fig. 1. Differences between simulated and observed topography at the end of the 20-kyr constant climate forcing model run applying the 8 atmospheric forcing fields. 


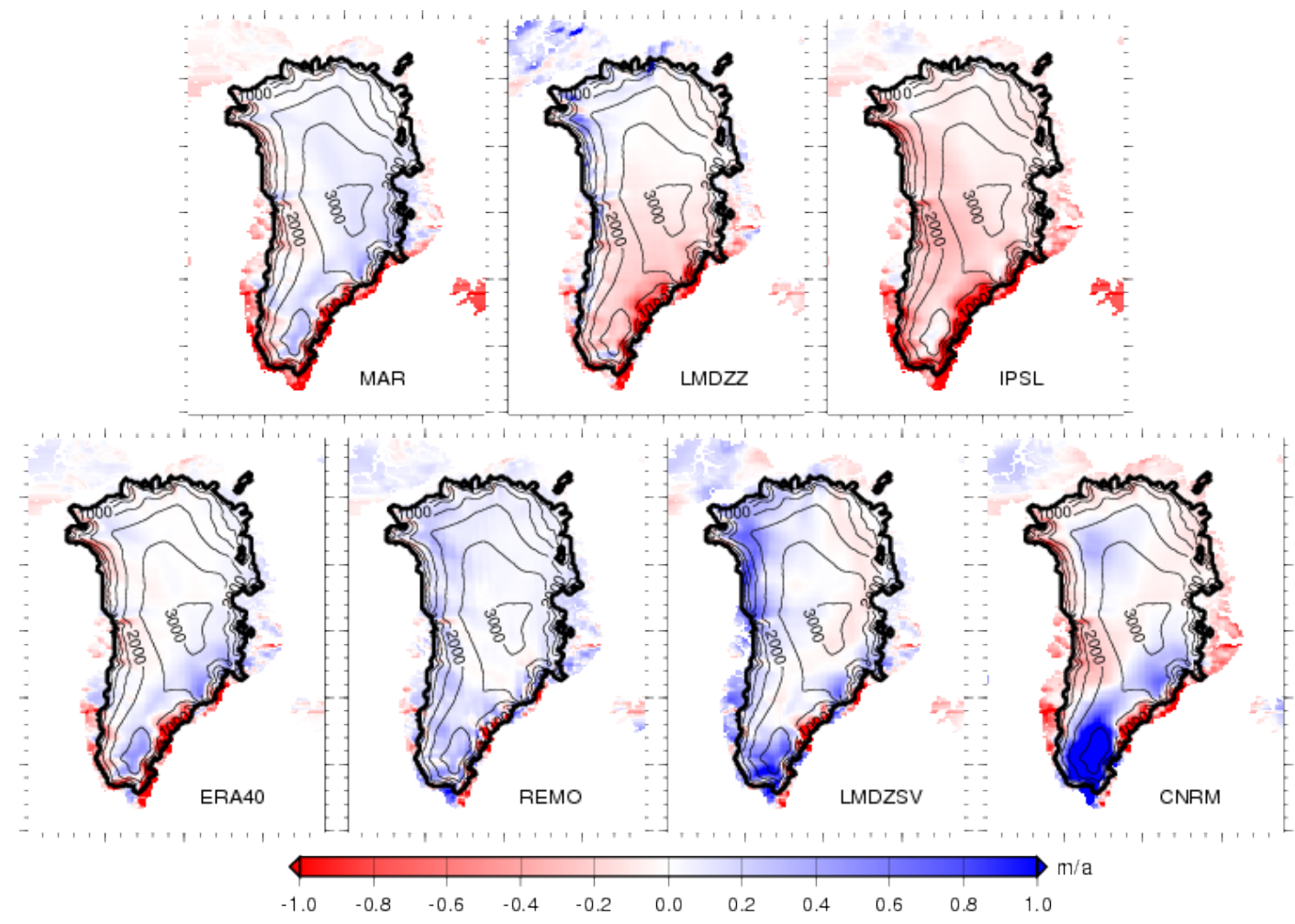

Fig. 2. Difference in climatological (1958-2009) annual precipitation rate between the RACMO model (Ettema et al., 2009) and the other forcing fields used in this study (in metres of ice equivalent). Except for the RACMO model, climatological means are evaluated on the 1980-1999 period. 


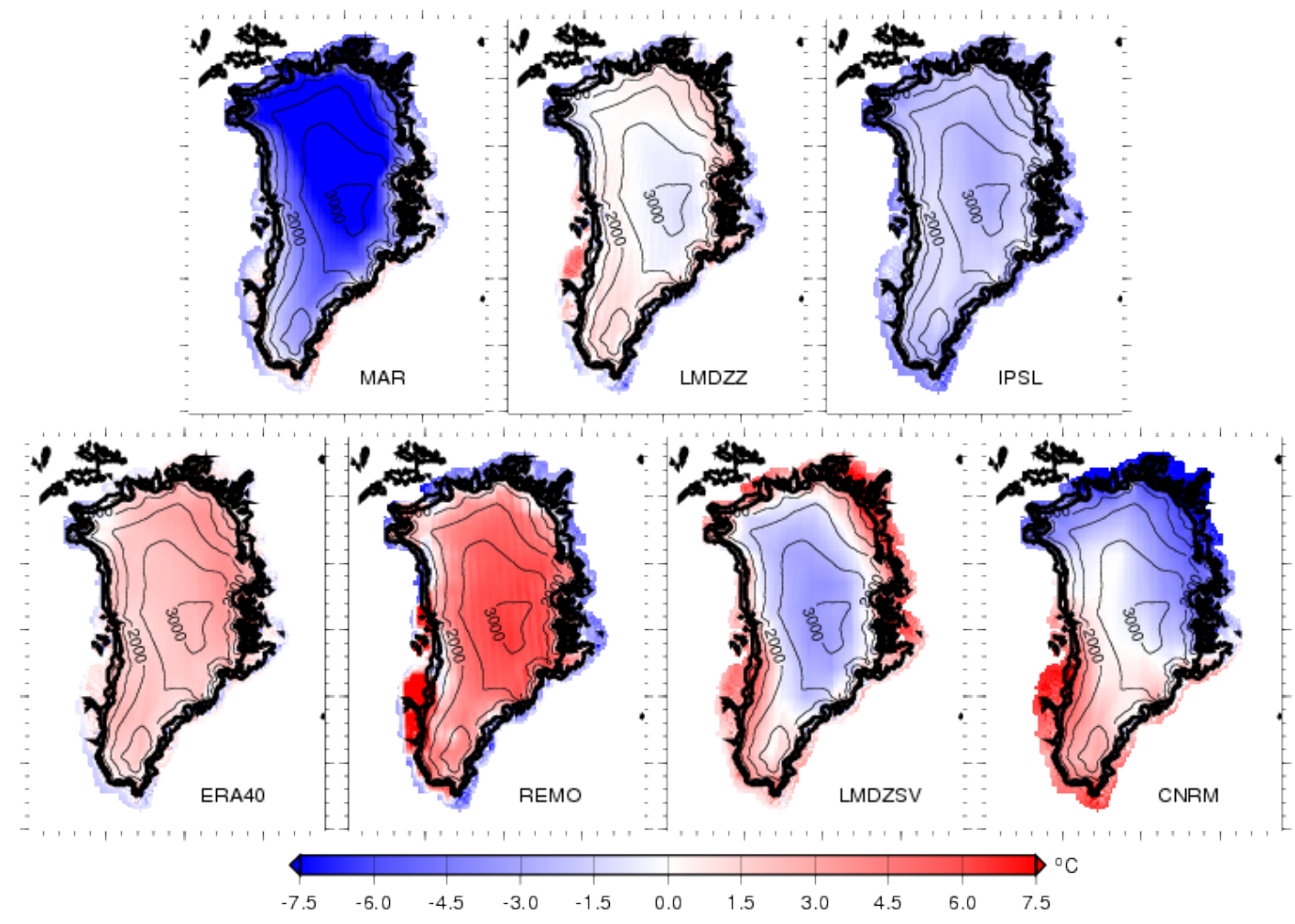

Fig. 3. Difference in mean July near surface temperature (Fausto et al., 2009) and the other forcing fields used in this study (in ${ }^{\circ} \mathrm{C}$ ). For the models, climatological means are evaluated on the 1980-1999 period, while the near surface air temperature field from Fausto et al. (2009) is representative of the 1996-2006 period. 